\title{
Tactile acuity and stereognosis in elderly with visual impairment
}

\author{
Kuo Chih Chien Michael ${ }^{*}$, Chan Hin Yu ${ }^{1}$, Ku Hiu Lam ${ }^{1}$, Siu Tsz Yan ${ }^{1}$, Wong Sin Yung ${ }^{1}$, Chiu Tat San Armstrong ${ }^{2}$ and Yeung King ${ }^{2}$ \\ ${ }^{1}$ School of Medical and Health Sciences, Tung Wah College, Hong Kong \\ ${ }^{2}$ The Hong Kong Society for the Blind, Hong Kong
}

\begin{abstract}
Several studies conducted previously showed that tactile acuity of blind individuals was enhanced. However, no study has investigated whether the effects of visual deprivation on tactile acuity can be extended to those with a visual impairment, but without true blindness. This study examined tactile acuity and stereognosis in elderly with visual impairment and those with normal vision. A total of 36 participated in the study and were divided into two groups: visually impairment and sighted groups. Their abilities were assessed by four assessments including two-point discrimination test, monofilament test (for touch pressure), tactile orientation discrimination test (by JVP domes), and stereognosis test. Results showed no significant difference in tactile abilities between visually impaired and sighted participants except in stereognosis. The enhancement in the ability for object recognition is particularly interesting and could be studied further in future research.
\end{abstract}

\section{Introduction}

Human beings are equipped with multiple senses and specialized sensory organs to interact with the multisensory world. When a person loses the ability to detect one type of sensory input, cortical compensation may be developed by using information obtained from other senses [1]. This was evidenced when comparing with sighted participants, superior performance was exhibited in the blind individuals in, for example, auditory pitch discrimination and pitchtimbre categorization tasks and motion perception task [2,3]. Cuevas et al. also showed similar results using an olfactory discrimination and identification paradigm [4].

Tactile sensations are classified into simple and complex stimuli sensations. Simple stimuli sensations include touch detection and sensitivity to pressure and vibration, while complex stimuli sensations include those for texture, spatial acuity and orientation, stereognosis, and manual exploration [5]. Tactile acuity refers to the precision that features on an item can be sensed or recognized by the hand [6]. Stereognosis is the ability to recognize and identify common objects through tactile manipulation without visual or auditory cues. This ability requires the integration all tactile sensations of the hand [5].

In regards to tactile sensations, a number of previous studies have reported superior performance (e.g., in duration and temporal discrimination, grading orientation discrimination, and 3D shape recognition) for the blind when compared to sighted individuals [710]. However, others reported no difference between the two groups of participants $[1,11,12]$. The discrepancies in these results can be accounted for by differences in methodology [10]. However, the questions still exist whether superior tactile acuity is possessed by blind adults compared to sighted persons. Previous studies about sensory deprivation and tactile acuity have been conducted in people with early, late, or congenital blindness. This investigation attempts to extend the studies about the effects of visual deprivation on tactile acuity to those with a visual impairment but without true blindness.

\section{Methodology}

\section{Participants}

There was a total of 36 visually impaired and sighted elderly who participated in this research. Twenty participants were assigned to the visual impairment group and the remaining 16 were assigned to the control group. Participants were assigned into either group according to the results from the visual acuity test or information collected from their medical record (including age, gender, educational level, visual acuity, medical history and present illnesses). Individuals whose visual acuity was worse than $20 / 60$ but have at least one eye better than no light perception (NLP) were assigned into the visual impairment group. Those who have visual acuity equals to or better than 20/60 were allocated into control group. Inclusion criteria were an age of 60 or above and no hand trauma or disabling conditions that would affect the function of the upper limbs. With reference to a similar study conducted previously, subjects would be excluded if they have diabetes [13]. All participants were recruited from local nursing homes, including a local society for the blind. All participants in visual impairment group and control group were right-handed. The study was approved by the Research Ethics Sub-Committee of the College. Written consent was gathered from all participants.

\section{Procedures}

Visual acuity test (e.g., Tumbling E chart) was conducted to differentiate participants into visually impaired or control groups. Each

${ }^{\star}$ Correspondence to: Kuo Chih Chien Michael, Tung Wah College, School of Medical and Health Sciences, 98 Shantung Street, Mongkok, Kowloon, Hong Kong, Tel: +852 3468 6656; Fax: +852 3753 2106; E-mail: michaelkuo@twc.edu.hk

Key words: tactile acuity, stereognosis, blind, visual impairment

Received: October 17, 2019; Accepted: October 31, 2019; Published: November 04,2019 
eye was tested separately. The eye not being tested was blocked. If the person being tested typically wears eyeglasses or contact lenses fulltime, the eyewear would be worn during the test.

A total of four tactile assessments were performed by participants: two-point discrimination test, monofilament test (for touch pressure), tactile grating orientation discrimination test (by JVP domes), and the stereognosis test. All participants were blindfolded when performing all the above tests. Two-point discrimination, monofilament, and tactile orientation discrimination tests were performed on finger pads of thumb, index and middle fingers of both hands.

A stereognosis kit was used for the evaluation. It consisted of 17 common items, such as pen, pencil, key, coins etc. For the purpose of this study, stereognosis test was modified slightly from standardized procedures established in a previous study [14]. The test began with placing first object in dominant hand. Participants had as much time as they wanted to feel that object and then gave their final answer to what they thought it was. The object would be taken from their hand and replaced by the next object after they gave their answer. This process was repeated until all objects had been tested in the dominant hand. Then, the same objects were used to test the non-dominant (left) hand.

\section{Data analysis}

Results from the two-point discrimination, tactile grating orientation discrimination, and stereognosis tests were analyzed using independent sample t-tests. Results from the monofilament test were analyzed using Mann-Whitney U test. Demographic data were also analyzed to check whether there was any difference in participant characteristics (i.e., gender proportion, age, and years of education).

\section{Results}

Table 1 shows the participant characteristics and assessment results from the four tactile tests. Between the control and visual impairment groups, there were no statistically significant differences in gender proportion $(p=0.1)$, age $(p=0.39)$, and years of education $(p=0.08)$. Significant differences were also not identified in the two-point discrimination ( $\left.p^{\prime} s>0.24\right)$, monofilament $\left(p^{\prime} s>0.21\right)$ and tactile grating orientation discrimination tests $\left(p^{\prime} s>0.22\right)$. Number of items participants were able to identify between the two groups was significantly different (right hand $p<0.05$, left hand $p<0.01$ ).

\section{Discussion}

To our knowledge, this is the first study that assessed visually impaired participants (with better vision than NLP) and sighted persons. From the comparisons made between the two groups of participants, significant results were not found in three, which tested simple stimuli sensations, of the four tactile assessments. These results indicated that this aspect of tactile sensations was not enhanced in this group of visually impaired participants. Along this line, Cattaneo, et al. [15] discovered that late-blind and sighted participants performed similarly in their tactile tasks, suggesting their tactile abilities did not have significant differences. Results from this investigation implied that true blindness (NLP) and the duration of vision impairment maybe important factors for developing potential tactile acuity enhancement. All of the participants in this study became visually impaired during adulthood, instead of having vision lost congenitally or early in life. Papagno, et al. [1] suggested that advantages in touch sensations are less likely to have emerged if people became visually impaired in adulthood, as cortical reorganization is more likely to occur in the early blind persons [16].
Table 1. Participant characteristics and assessment results

\begin{tabular}{|c|c|c|c|}
\hline $\begin{array}{l}\text { Demographics and } \\
\text { test Scores }\end{array}$ & & $\begin{array}{c}\text { Control } \\
n=16\end{array}$ & $\begin{array}{l}\text { Visually impaired } \\
\text { participants } n=20\end{array}$ \\
\hline Sex (women), \% & & 81.3 & 55 \\
\hline Age (years), mean \pm SD (range) & & $85.8 \pm 7.8(71-94)$ & $83.5 \pm 9.3(62-99)$ \\
\hline Education (years), (range) & & $0.75(0-6)$ & $3(0-10)$ \\
\hline \multirow[t]{6}{*}{$\begin{array}{l}\text { 2-point discrimination }(\mathrm{mm}) \text {, } \\
\text { mean }\end{array}$} & Right thumb & 4.2 & 4.7 \\
\hline & Left thumb & 4.1 & 4.3 \\
\hline & Right index & 4.1 & 4.8 \\
\hline & Left index & 4.2 & 4.9 \\
\hline & Right middle & 4.4 & 5.0 \\
\hline & Left middle & 4.4 & 4.7 \\
\hline \multirow[t]{6}{*}{ Monofilament $(g)$, median } & Right thumb & 0.16 & 0.16 \\
\hline & Left thumb & 0.16 & 0.31 \\
\hline & Right index & 0.16 & 0.16 \\
\hline & Left index & 0.16 & 0.16 \\
\hline & Right middle & 0.16 & 0.16 \\
\hline & Left middle & 0.16 & 0.16 \\
\hline \multirow[t]{6}{*}{$\begin{array}{l}\text { Grating orientation discrimination } \\
(\mathrm{mm}) \text {, mean }\end{array}$} & Right thumb & 3.4 & 3.5 \\
\hline & Left thumb & 3.8 & 3.6 \\
\hline & Right index & 3.8 & 3.6 \\
\hline & Left index & 3.9 & 3.7 \\
\hline & Right middle & 3.8 & 3.8 \\
\hline & Left middle & 3.9 & 3.8 \\
\hline \multirow[t]{2}{*}{$\begin{array}{l}\text { Stereognosis (number), mean } \pm \mathrm{SD} \\
\text { (range) }\end{array}$} & Right hand & $11.4 \pm 3.4(3-17)$ & $13.5 \pm 2.1(9-17)^{*}$ \\
\hline & Left hand & $11.9 \pm 3.2(4-16)$ & $14.3 \pm 1.9(11-17)^{* *}$ \\
\hline
\end{tabular}

In this experiment, it was also found that visual impairment group performed more superiorly in the stereognosis task. Few studies have evaluated stereognosis in the blind. Norman and Bartholomew [10], however, examined a similar concept, abilities to discriminate $3 \mathrm{D}$ shapes, in their blind and control participants. Their results in the late onset blindness group, that was similar to ours, indicated that the ability to discriminate $3 \mathrm{D}$ shape was enhanced and that early visual experience may be needed to facilitate the development of this ability, as the enhancement was not identified in their congenitally blind participants. Our results indicated that a certain amount of visual deprivation can already enhance the ability to recognize objects.

In general, visually impaired participants outperformed sighted controls on the task involving stereognosis but not on two-point discrimination, touch pressure, or tactile grating orientation discrimination. The enhancement in ability for object recognition is particularly interesting and could be studied further in future research.

\section{References}

1. Papagno C, Cecchetto C, Pisoni A (2016) Deaf, blind or deaf-blind: Is touch enhanced? Exp Brain Res 234: 627-636. [Crossref]

2. Wan CY, Wood AG, Reutens DC, Wilson SJ (2010) Congenital blindness leads to enhanced vibrotactile perception. Neuropsychologia 48: 631-635.

3. Lewald J (2013) Exceptional ability of blind humans to hear sound motion: implications for the emergence of auditory space. Neuropsychologia 51: 181-186.

4. Cuevas I, Plaza P, Rombaux P, De Volder AG, Renier L (2009) Odour discrimination and identification are improved in early blindness. Neuropsychologia 47: 3079-3083.

5. Bleyenheuft Y, Gordon AM (2013) Precision grip control, sensory impairments and their interactions in children with hemiplegic cerebral palsy: a systematic review. Res Dev Disabil 34: 3014-3028. 
6. Catley MJ, O'Connell NE, Berryman C, Ayhan FF, Moseley GL (2014) Is tactile acuity altered in people with chronic pain? a systematic review and meta-analysis. J Pain 15: 985-1000. [Crossref]

7. Van Boven RW, Hamilton RH, Kauffman T, Keenan JP, Pascual-Leone A (2000) Tactile spatial resolution in blind braille readers. Neurology 54: 2230-2236. [Crossref]

8. Stilla R, Hanna R, Hu X, Mariola E, Deshpande G, et al. (2008) Neural processing underlying tactile microspatial discrimination in the blind: a functional magnetic resonance imaging study. $J$ Vis $8: 1-19$. [Crossref]

9. Van der Lubbe RH, Van Mierlo CM, Postma A (2010) The involvement of occipital cortex in the early blind in auditory and tactile duration discrimination tasks. $J \operatorname{Cog} n$ Neurosci 22: 1541-1556.

10. Norman JF, Bartholomew AN (2011) Blindness enhances tactile acuity and haptic 3-D shape discrimination. Atten Percept Psychophys 73: 2323-2331. [Crossref]
11. Grant AC, Thiagarajah MC, Sathian K (2000) Tactile perception in blind Braille readers: a psychophysical study of acuity and hyperacuity using gratings and dot patterns. Percept Psychophys 62: 301-312. [Crossref]

12. Alary F, Duquette M, Goldstein R, Chapman CE, Voss P, et al. (2009) Tactile acuity in the blind: a closer look reveals superiority over the sighted in some but not all cutaneous tasks. Neuropsychologia 47: 2037-2043. [Crossref]

13. Goldstein EB (2009) Encyclopedia of perception. Sage

14. Reidy M, Kinane J, Bradley D, Harbison J, McDonagh R (2016) Cold, hard cash Clinical assessment of stereognosis using common objects and coins in older subjects. Age Ageing 7: 180-182. [Crossref]

15. Cattaneo Z, Vecchi T, Fantino M, Herbert AM, Merabet LB (2013) The effect of vertical and horizontal symmetry on memory for tactile patterns in late blind individuals. Atten Percept Psychophys 75: 375-382.

16. D'Angiulli A, Waraich P (2002) Enhanced tactile encoding and memory recognition in congenital blindness. Int J Rehabil Res 25: 143-145.

Copyright: $(02019$ Kuo MCC. This is an open-access article distributed under the terms of the Creative Commons Attribution License, which permits unrestricted use, distribution, and reproduction in any medium, provided the original author and source are credited. 